\title{
PENINGKATAN KUALITAS HIDUP LANSIA DENGAN POSYANDU KELILING PADA MASA PANDEMI DI DESA JOGOROTO JOMBANG
}

\author{
IMPROVING THE QUALITY OF LIFE FOR THE ELDERLY WITH \\ POSYANDU MOBILE DURING THE PANDEMIC IN JOGOROTO \\ JOMBANG VILLAGE
}

\author{
Nanin Fauziah $^{1}$, Diah Mei Ratih Wulandari ${ }^{2}$, Dyah Ratna Alvia ${ }^{3}$, Eka Evin \\ Lina Sugiati ${ }^{4}$, Yunus Zakaria ${ }^{5}$,Shanti Rosmaharani ${ }^{6}$ \\ STIKES PEMKAB JOMBANG \\ Email : pkmpmposling@gmail.com
}

\begin{abstract}
ABSTRAK
Lanjut usia sebagai tahap akhir siklus kehidupan merupakan tahap perkembangan normal yang akan dialami oleh setiap individu yang mencapai usia lanjut. Upaya pemanfaatan pelayanan posyandu lansia perlu mendapatkan perhatian serius dan menjadi bagian dari strategi dalam peningkatan kualitas hidup lansia melalui upaya promotif dan preventif. Di masa Pandemi COVID-19 ini, kegiatan posyandu lansia banyak yang dihentikan karena mengurangi resiko penularan. Hal ini menyebabkan kurangnya perhatian terhadap kesehatan lansia yang rentan terhadap penyakit. Tujuan posyandu keliling ini adalah dengan menghidupkan kembali posyandu lansia, namun dengan metode yang berbeda dari sebelumnya. Metode yang digunakan dalam kegiatan ini yaitu dengan Posyandu Keliling pada lansia secara door to door dari satu rumah ke rumah yang lainnya terutama pada lansia yang beresiko dengan tetap menerapkan protokol kesehatan ketat. Kegiatan ini berkolaborasi dengan perawat lansia, bidan desa, dan kader desa serta berkoordinasi dengan puskesmas Mayangan. Hasil kegiatan ini di dapatkan status kesehatan yang stabil meliputi tekanan darah, kadar gula, asam urat dan kolesterol pada lansia Desa Jogoroto dalam jangka waktu pemantauan selama 3 bulan. Mitra memiliki sikap antusias yang tinggi dalam mengikuti kegiatan ini dan mitra dapat mengetahui status kesehatannya sehingga status kesehatannya lebih terkontrol. Kesimpulan program ini berfungsi untuk memantau status kesehatan lansia selama posyandu belum aktif kembali dan kegiatan ini diharapkan dapat berkelanjutan dan dapat berkontribusi membantu pelayanan kesehatan terkait..
\end{abstract}

Kata Kunci : Lansia, Posyandu keliling, Kualitas hidup

\begin{abstract}
ABSTRAC
Elderly as the final stage of the life cycle is a normal stage of development that will be experienced by every individual who reaches old age. Efforts to use Integrated Healthcare Center services for the elderly need to get serious attention and become part of the strategy in improving the quality of life of the elderly through promotive and preventive efforts. During this COVID-19 pandemic, many elderly Integrated Healthcare Center activities have been stopped because they reduce the risk of transmission. This causes a lack of attention to the health
\end{abstract}


of the elderly who are susceptible to disease. The purpose of this mobile Integrated Healthcare Center is to revive the elderly Integrated Healthcare Center, but with a different method than before. The method used in this activity is the Mobile Integrated Healthcare Center for the elderly by door to door from one house to another, especially for the elderly who are at risk while still implementing strict health protocols. This activity collaborates with elderly nurses, village midwives, and village cadres and coordinates with the Mayangan Health Center. The results of this activity obtained a stable health status including blood pressure, sugar levels, uric acid and cholesterol in the elderly in Jogoroto Village within a monitoring period of 3 months. Partners have a high enthusiasm for participating in this activity and partners can find out their health status so that their health status is more controlled. The conclusion of this program is to monitor the health status of the elderly as long as the Integrated Healthcare Center has not been active again and this activity is expected to be sustainable and can contribute to assisting related health services.

Keywords: Elderly, Mobile Integrated Healthcare Center, Quality of life

\section{PENDAHULUAN}

Lanjut usia (lansia) sebagai

tahap akhir siklus kehidupan merupakan tahap perkembangan normal yang akan dialami oleh setiap individu yang mencapai usia lanjut dan merupakan kenyataan yang tidak dapat dihindari. Berdasarkan pengelompokan usianya lansia dibagi menjadi : pralansia (usia 45-59 tahun), lansia (usia 60 tahun atau lebih), dan lansia risiko tinggi (usia 70 tahun atau lebih) (Depkes RI, 2003). Menurut Undang-Undang Republik Indonesia Nomor 13 tahun 1998 tentang Kesejahteraan Lanjut Usia, yang dimaksud dengan Lanjut Usia (Lansia) adalah seseorang yang telah mencapai usia 60 tahun ke atas, sedangkan menurut World Health Organisation (WHO) lanjut usia meliputi : usia pertengahan (middle age) yaitu kelompok usia 45 - 59 tahun, usia lanjut (elderly), kelompok usia 60 - 70 tahun, dan usia tua (old) yaitu kelompok usia antara $75-90$ tahun, serta usia sangat tua (very old), kelompok usia diatas 90 tahun (Sutikno, 2011).

Pada era pandemi saat ini, kelompok lansia merupakan kelompok yang paling beresiko mengalami peningkatan penyakit degeneratif. Semakin bertambahnya usia menyebabkan imunitas tubuh lansia cenderung ikut melemah sehingga semakin rentan terhadap beberapa keluhan fisik dan psikis yang akan menjadikan tergantung pada orang lain secara perlanan. Kesehatan pada lansia di Masa Pandemi COVID-19 ini tidak bisa diabaikan dan merupakan salah satu golongan masyarakat yang layak mendapatkan perhatian lebih.

Banyak lansia yang terkena penyakit degeneratif seperti reumatix, ostheoporosis, penyakit jantung, dibetes militus, hipertensi, inkontinensia urine, dan kanker. Penykait degeneratif mendapat sorotan utama pada lansia karena apabila penyakit ini tidak dikenali maka akan memberikan dampak 
negatif untuk kelanjutannya dan beberapa penyakit degeneratif adalah penyebab utama kematian lansia (Dwi, 2020). Berdasarkan data Riskesdas tahun 2018 di dapatkan data bahwa status permasalahan kesehatan pada lansia di Indonesia adalah : Penyakit tidak menular didapatkan data yaitu Asma 3,4\%, Kanker 4,62\%, Diabetes 6,29\%, Jantung 3,9\%, Hipertensi 18,31\%, Stroke 32,4\%, Gagal Ginjal Kronis 0,72\%, Penyakit sendi 15,55\%. Di indonesia, proporsi disabilitas pada penduduk lansia juga didapatkan data $1 \%$ menunujukkan tingkat berat dan $1,6 \%$ menunjukkan tingkat ketergantungan total.

Untuk mendukung kesehatan lansia dan menjalankan amanat Undang-Undang Nomor 13 Tahun 1998 tentang kesejahteraan lanjut usia, kementrian kesehatan (kemkes) membentuk pos pelayanan terpadu (posyandu) lansia yang penyelenggaraannya melalui program pusat kesehatan masyarakat (puskesmas). Pada prakteknya, posyandu lansia melibatkan peran serta para lansia, keluarga, tokoh masyarakat, dan organisasi sosial. Di masa pandemi, posyandu lansia memang banyak mengalami hambatan bahkan ditiadakan untuk sementara.. Hal ini mengakibatkan berhentinya pemantauan kesehatan secara rutin dan pemberian health education. Sehingga menyebabkan kurangnya perhatian terhadap kesehatan lansia yang rentan terhadap penyakit. Hal tersebut berujung angka penyakit degenaratif yang awalnya dikendalikan menjadi semakin meningkat. Posyandu lansia juga sebagai wadah bertemu dengan teman sebayanya, lansia bisa saling berkomunikasi, pada masa pandemi ini mereka merasa kesepian karena tidak bisa berkumpul.

Sejak kebijakan sosial distancing diterapkan, sejumlah posyandu lansia harus berhenti beroperasi. Namun, mengingat lansia adalah golongan rentan, menghidupkan kembali posyandu ini menjadi satu alternatif untuk turut menekan penularan COVID-19 pada golongan lansia. Program posyandu keliling dengan mendatangi lansung rumah lansia dapat menjadi salah satu strategi dalam upaya peningkatan kualitas hidup lansia. Mengingat tidak semua lansia mengetahui informasi posyandu lansia, diharapkan adanya para kader yang dilatih dengan baik dan memiliki tanggung jawab melindungi golongan lansia, dapat menjadi jembatan yang baik antara petugas kesehatan dengan para lansia. Posyandu Keliling ini diharapkan lansia mampu melakukan kegiatan yang positif dan mampu menerapkan hidup sehat di masa Pandemi COVID-19, meskipun posyandu lansia dilakukan secara keliling dari rumah ke rumah dengan tetap menerapkan protokol kesehatan yang ketat. 


\section{METODE PELAKSANAAN}

Pada kegiatan ini metode yang digunakan yaitu dengan Posyandu Keliling pada lansia secara Door to Door dari satu rumah ke rumah yang lainnya. Kegiatan ini berkolaborasi dengan perawat lansia, bidan desa, dan kader desa. Media yang digunakan pada kegiatan ini berupa modul leaflet, power point, maupun video tutorial senam lansia yang sudah terupload di youtube pkm pm posling. Pertama kegiatan sosialisasi dengan kepala desa, bidan desa, dan kader lansia yang dilakukan secara Daring melalui Vidio Call. Kedua kegiatan penyuluhan yang berupa pemberian materi dan pelatihan cek tekanan darah, cek kolesterol, cek gula darah, dan cek asam urat. Ketiga kegiatan pelatihan senam diabetes, senam kagel, dan senam persendian kepada ibu-ibu kader lansia, dengan tujuan agar kader dapat memutar kembali vidio dengan link https://youtu.be/pyE3cJE3Jis dari

\section{HASIL KEGIATAN}

Kegiatan pengabdian masyarakat ini dilaksanakan di Desa Jogoroto pada tanggal 11 Juni 2021 yang diikuti oleh perawat lansia, bidan desa, dan kader desa dengan target sasaran 20 lansia. Kegiatan ini diawali dengan sosialisasi pada kader lansia dan kepala desa yang disampaikan oleh tim pelaksana secara daring melalui Video Call. Dilanjutkan pada tanggal 12 Juni 2021 yaitu Kegiatan penyuluhan tentang materi penyakit degeneratif (hipertensi, diabetes militus, ghout youtube pkm pm posling. Keempat kegiatan pendampingan pelaksanaan program Posyandu keliling ke rumah lansia selama 4 minggu, 1 kader didampingi oleh 2 pelaksana dengan target 4 rumah perhari.

\section{Sasaran Kegiatan Pengabdian Masyarakat}

Target sasaran yang diambil pada kegiatan ini yaitu 20 lansia di Desa Jogoroto. Kegiatan ini berkolaborasi dengan perawat lansia, bidan desa, dan kader desa.

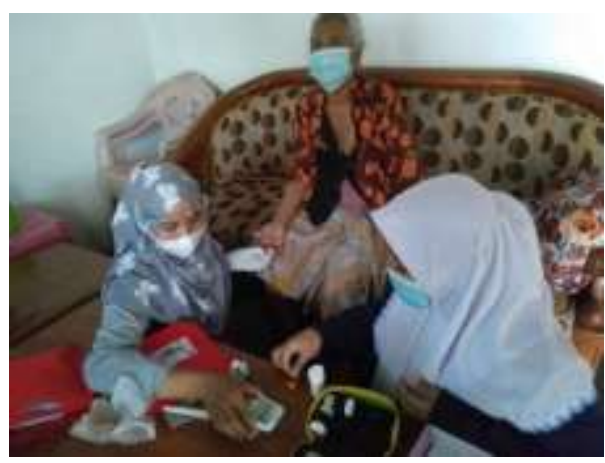

\section{Gambar 1. Pelaksanaan Program di Posyandu 2}

artritis, dan inkontenensia urin) dan dilanjutkan dengan pelatihan pada kader untuk kegiatan Posyandu keliling secara langsung dengan menggunakan protokol kesehatan yang ketat. Pelatihan pada kader 3 hari sekali maksimal 3 jam selama 2 minggu yang meliputi tekanan darah dan timbangan dan cek kolestrol, gula darah, asam urat. Seluruh kader merespon dengan baik dan mendengarkan pemaparan dari Tim Pelaksana dengan antusias. Setelah kegiatan selesai, tim pelaksana mengevaluasi kembali kegiatan yang telah dilakukan untuk mengetahui 
pemahaman kader. Pada tanggal 18 Juni dilanjutkan dengan kegiatan pelatian senam lansia pada kader (senam kegel, senam kaki diabetes, senam persendian). Pada tanggal 2429 Juni 2021 pendampingan pelaksanaan program Posyandu keliling ke rumah lansia selama 4 minggu, 1 kader didampingi oleh 2 pelaksana dengan target 4 rumah perhari. Seluruh kader dan lansia

\section{PEMBAHASAN}

Lansia merupakan seseorang yang telah memasuki usia 60 tahun keatas. Lansia merupakan kelompok umur pada manusia yang telah memasuki tahapan akhir dari fase kehidupannya. Kelompok yang dikategorikan lansia ini akan terjadi suatu proses yang disebut Aging Process atau proses penuaan (Notoatmodjo, 2014). Berkaitan dengan status kesehatan pada lansia, saat ini pemerintah telah merencanakan program peningkatan derajat kesehatan khusus lansia melalui posyandu lansia.

Posyandu lansia adalah pos pelayanan terpadu untuk masyarakat usia lanjut di suatu wilayah tertentu yang sudah disepakati oleh masyarakat (Depkes RI. 2013). Upaya pemanfaatan pelayanan posyandu lansia perlu mendapatkan perhatian serius dan menjadi bagian dari strategi dalam peningkatan kesejahteraan lansia melalui upaya promotif dan preventif atau yang biasa disebut paradigma sehat (Henniwati, 2008). Mengingat fisik lansia yang lemah sehingga mereka tidak dapat leluasa menggunakan berespon positif dan sangat antusias dalam mengikuti kegiatan ini.

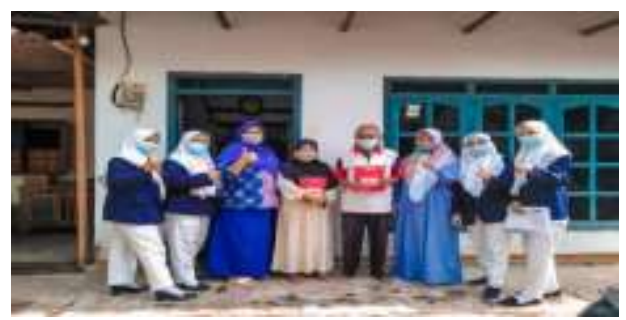

Gambar 2. Pelaksanaan posyandu keliling

sarana dan prasarana maka upaya pemanfaatan pelayanan posyandu lansia yaitu dengan menyediakan sarana dan fasilitas khusus bagi lansia.

Di masa Pandemi COVID-19 ini, kegiatan posyandu lansia banyak yang dihentikan karena mengurangi resiko penularan. Hal ini tentu menyebabkan kurangnya perhatian terhadap kesehatan lansia yang rentan terhadap penyakit. Tutupnya posyandu lansia praktis mengakibatkan berhentinya pula pemantauan kesehatan rutin, pemberian promosi kesehatan dan health education sehingga banyak lansia dan keluarga yang pada akhirnya mengabaikan pada kesehatannya. Hal tersebut berujung angka kesakitan penyakit degenaratif yang awalnya dikendalikan menjadi makin meningkat. Selain itu pada lansia biasanya juga mengalami perubahan secara emosional dimana pada usia yang relatif tua, banyak lansia yang merasa kesepian sehingga posyandu sebagai sarana sosialisasi dan interaksi sesama lansia yang membuat lansia menjadi 
bahagia. Dampak negatif dari ditutupnya posyandu lansia, maka lansia dapat merasa semakin kesepian dan beresiko terjadi demensia/pikun. Hal yang terjadi adalah pemberian health education tentang covid akhirnya juga menjadi kurang maksimal. Akibatnya kurangnya perhatian lansia dalam melakukan kegiatan sehari-hari tanpa memperhatikan protokol kesehatan dan kurang memperhatikan kesehatan tubuhnya. Sementara di sisi lain, keadaan seperti ini lansia sangat berisiko mudah tertular COVID-19. Upaya pemberdayaan kesehatan lansia harusnya dapat dilakukan dengan tetap mematuhi protokol kesehatan dengan ketat, dan dapat diaplikasikan dalam aktivitas sehari-hari. Dengan harapan dapat terjaganya kesehatan lansia dari berbagai macam penyakit degeneratif dan resiko penularan COVID-19.

Upaya pemberdayaan kesehatan lansia ini salah satunya adalah dengan menghidupkan kembali posyandu lansia, namun dengan metode yang berbeda dari sebelumnya. Upaya ini melibatkan kader, lansia, keluarga, dan lingkungan masyarakat. Hal tersebut untuk mengurangi resiko terjadinya penularan COVID-19 dan kekambuhan penyakit degeneratif pada lansia. Mahasiswa menggalakkan upaya peningkatan kualitas hidup lansia dengan Posyandu Keliling di masa pandemi. Dengan adanya Posyandu Keliling ini diharapkan lansia mampu melakukan kegiatan yang positif dan mampu menerapkan hidup sehat di masa Pandemi COVID-19, meskipun posyandu lansia dilakukan secara keliling dari rumah ke rumah dengan tetap menerapkan protokol kesehatan yang ketat.

Kegiatan ini salah satunya
adalah dengan menghidupkan kembali posyandu lansia, namun dengan metode yang berbeda dari sebelumnya. Upaya ini melibatkan kader, lansia, keluarga, dan lingkungan masyarakat. Hal tersebut untuk mengurangi resiko terjadinya penularan COVID-19 dan kekambuhan penyakit degeneratif pada lansia. Mahasiswa menggalakkan upaya peningkatan kualitas hidup lansia dengan Posyandu Keliling di masa pandemi. Dengan adanya Posyandu Keliling ini diharapkan lansia mampu melakukan kegiatan yang positif dan mampu menerapkan hidup sehat di masa Pandemi COVID-19, meskipun posyandu lansia dilakukan secara keliling dari rumah ke rumah dengan tetap menerapkan protokol kesehatan yang ketat.

\section{KESIMPULAN}

1. Monitoring kesehatan lansia yang terdaftar pada posyandu lansia Desa Jogoroto dilakukan satu bulan sekali agar status kesehatan lansia menjadi meningkat.

2. Penanganan dan tindak lanjut juga diperlukan ketika penyakit degeneratif semakin meningkat dengan menghidupkan kembali 
posyandu lansia yang berhenti di Masa Pandemi COVID-19 dengan metode yang berbeda.

3. Dengan adanya penyuluhan dan pelatihan mampu meningkatkan pengetahuan dan skill pada kader lansia dan dapat mengaplikasikan pengetahuan tersebut untuk membantu monitoring kesehatan lansia.

\section{SARAN}

Saran untuk pengabdian masyarakat ini adalah diperlukan dukungan dan kerjasama dari pihak Kader, perawat lansia, Bidan, dan Lansia Desa Jogoroto. Kegiatan ini dilakukan secara berkala setiap satu bulan sekali untuk memonitoring status kesehatan lansia terkait dengan penyakit degeneratif. Kegiatan ini tetap mematuhi protokol kesehatan dengan ketat.

\section{DAFTAR PUSTAKA}

Notoatmodjo. 2014. Lansia adalah-Pengertian, Makalah, Klasifikasi Dan Kesehatan.Jakarta. Metodologi Penelitian Kesehatan

$$
\text { Kementeri an Kesehatan. }
$$

2010. Peran dan Pelayanan Posyandu Lansia dalam MasyarakatSehat- $Q$

Kementerian Kesehatan RI. 2013. Situasi dan Analisis Lanjut Usia. Diakses pada 30 September 2015.

Dinas Kesehatan DIY. 2012.

Profil Kesehatan Penduduk

Indonesia. Departemen Kesehatan Provinsi DIY. 